\title{
Bioactive Ti and its Alloys by Different Surface Treatments
}

\author{
J.C.Mirza Rosca* , J. Rodriguez Castro ${ }^{*}$ and E.D. Herrera Santana* \\ * Dept. of Mechanical Engineering, University of Las Palmas de Gran Canaria, Tafira, 35017, Spain
}

Titanium and titanium alloys being bioinert materials, they do not form a chemical bond with bonny tissue. Therefore, they must be fixed to bone by mechanical interloking in clinical use, and the possibility of loosening over a long period may become a critical problem. Bioactive materials such as hydroxyapatite and certain glasses or glass-ceramics have been reported to form tight chemical bonds with bone tissue and are widely used to fill bone defects. However, owing to their brittle nature, they are useful only in applications where the mechanical forces are nonexistent or primarily compressive. For the load-bearing parts of skeleton being replaced, titanium and its alloys are the best but a surface preparation is necessary.

Titanium and two new alloys of titanium: Ti-5Al-4V and Ti-6Al-4Fe with different surface treatments were studied. In one of the treatments the samples are immersed in $\mathrm{H}_{2} \mathrm{SO}_{4} 3 \mathrm{M}$, as anode, and a platinum electrode is used as cathode, for 1 minute at 60 volts. After the attack, were washed with distilled water and dried at $40^{\circ} \mathrm{C}$ during 24 hours. In the other treatment the samples were immersed in $\mathrm{NaOH} 10 \mathrm{M}$ at $60^{\circ} \mathrm{C}$ for 24 hours After the attack, were washed with distilled water and dried at $40^{\circ} \mathrm{C}$ during 24 hours.

With $\mathrm{H}_{2} \mathrm{SO}_{4}$ ataque, the $\mathrm{TiO}_{2}$ is formed on the surface (can be seen different colours depending on the thickness of the film). The surface of the samples subjected to the $\mathrm{NaOH}$ treatment is covered with a sodium titanate layer and rutile $\left(\mathrm{TiO}_{2}\right)$. The microscopical aspects of the surfaces are presented in Fig.1.

The surfaces were observed using an optical microscope and the microhardness measurements were performed tangentially to the surface with a Vickers indenter applied at every $0.5 \mathrm{~mm}$ along the diameter of the sample. Loads of 10,25, 50 and 200 grams and dwell time of $15 \mathrm{sec}$. were used. The average value for each sample, expressed as hardness Vickers degree (HV) was calculated; based on this average value, the corresponding depth was calculated. For the $\mathrm{NaOH}$ atack was observed the presence of two phases: one soft and one hard and the correspondence values of microhardness and the average depths are presented in the Table 1.

The tensile strength results are presented in the Table 2 . The alloys exhibit brittle fracture and yield stress was equated to ultimate tensile stress. The tensile strength of the alloys can be considered good in relation with other similar implant materials. The open circuit potential (OCP) variation over 45 days of immersion in artificial saliva is determined. A rapid variation of the potential is observed within the first 100 hours of immersion and steady-state values after 20 days range from 60 to $80 \mathrm{mV}$ versus SCE.

It can be concluded that: a) the alloys formed a hard layer on their surface which greatly improves the wear resistance; b) the microhardness values for the samples with $\mathrm{H}_{2} \mathrm{SO}_{4}$ attack are almost the same, so the surface is covered in these cases with $\mathrm{TiO}_{2}$; c) the average value for the samples with $\mathrm{NaOH}$ is not available (big dispersion in the values) so, it can be detected the presence 
of two different phases: one with the same hardness like $\mathrm{TiO}_{2}$ and other, harder, sodium titanate; d) the surface of the sample can be hardened significantly by $\mathrm{NaOH}$ treatment by forming the sodium titanate.

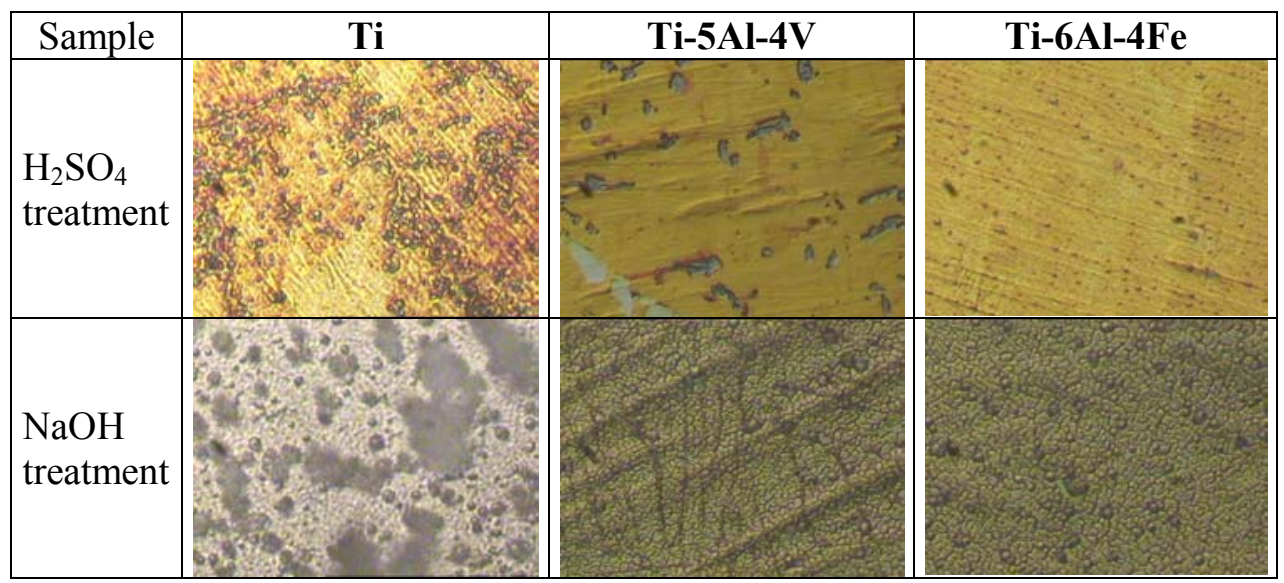

Fig.1. Optical micrograph $(\mathrm{x} 3000)$ of the surface.

Table1. Average values of microhardness and corresponding penetration depths

\begin{tabular}{|c|c|c|c|c|c|c|c|c|c|}
\hline \multirow{3}{*}{ Sample } & \multirow{3}{*}{ Load } & \multirow{2}{*}{\multicolumn{2}{|c|}{$\begin{array}{l}\text { H2SO4 } \\
\text { ataque }\end{array}$}} & \multirow{2}{*}{\multicolumn{2}{|c|}{$\begin{array}{l}\mathrm{NaOH} \\
\text { ataque }\end{array}$}} & \multicolumn{4}{|c|}{$\mathrm{NaOH}$ ataque } \\
\hline & & & & & & \multicolumn{2}{|c|}{ Soft phase } & \multicolumn{2}{|c|}{ Hard phase } \\
\hline & & HV & $d(\mu)$ & $\mathrm{HV}$ & $\mathrm{d}(\mu)$ & $\mathrm{HV}$ & $d(\mu)$ & $\mathrm{HV}$ & $d(\mu)$ \\
\hline \multirow{4}{*}{$\mathbf{T i}$} & 10 & 140 & 1.64 & 172 & 1.48 & 160 & 1.54 & 198 & 1.38 \\
\hline & 25 & 180 & 2.29 & 197 & 2.19 & 159 & 2.44 & 217 & 2.09 \\
\hline & 50 & 180 & 3.24 & 200 & 3.08 & 170 & 3.34 & 227 & 2.89 \\
\hline & 200 & $182^{*}$ & 4.56 & 194 & 6.25 & 177 & 6.54 & 225 & 5.80 \\
\hline \multirow{4}{*}{ Ti-5Al-4V } & 10 & 287 & 1.15 & 332 & 1.07 & 284 & 1.15 & 372 & 1.01 \\
\hline & 25 & 378 & 1.58 & 450 & 1.45 & 390 & 1.56 & 510 & 1.36 \\
\hline & 50 & 401 & 2.17 & 485 & 1.98 & 461 & 2.03 & 501 & 1.94 \\
\hline & 200 & $387^{*}$ & 3.13 & 420 & 4.24 & 393 & 4.39 & 480 & 3.97 \\
\hline \multirow{4}{*}{ Ti-6Al-4Fe } & 10 & 294 & 1.13 & 241 & 1.25 & 198 & 1.38 & 265 & 1.19 \\
\hline & 25 & 322 & 1.71 & 311 & 1.74 & 281 & 1.83 & 349 & 1.65 \\
\hline & 50 & 339 & 2.36 & 350 & 2.32 & 314 & 2.45 & 413 & 2.14 \\
\hline & 200 & $350^{*}$ & 3.29 & 315 & 4.90 & 266 & 5.33 & 343 & 4.70 \\
\hline
\end{tabular}

Table 2. Tensile strength measurement of the alloys

\begin{tabular}{|c|c|c|c|c|c|c|c|}
\hline $\begin{array}{c}\text { Sample - } \mathrm{d}_{\mathrm{o}} \\
(\mathrm{mm})\end{array}$ & $\begin{array}{c}\mathrm{S}_{\mathrm{o}} \\
(\mathrm{mm})\end{array}$ & $\begin{array}{c}\mathrm{L}_{\mathrm{c}} \\
(\mathrm{mm})\end{array}$ & $\begin{array}{c}\mathrm{L}_{\mathrm{o}} \\
(\mathrm{mm})\end{array}$ & $\mathrm{K}^{\prime}$ & $\mathrm{F}_{\max }(\mathrm{KN})$ & $\begin{array}{c}\mathrm{R}_{\mathrm{m}} \\
\left(\mathrm{Kgf} / \mathrm{mm}^{2}\right)\end{array}$ & $\mathrm{A} \%$ \\
\hline Ti-5Al-4V - 6 & 28.27 & 102 & 90 & 15 & 297.5 & 104.35 & 1.6 \\
\hline Ti-6Al-4Fe - 20 & 314.16 & 118 & 100 & 5 & 253.8 & 82.40 & - \\
\hline
\end{tabular}

